\title{
Descriptive analysis of Overall Equipment Effectiveness (OEE) in various industry
}

\author{
S T Risyahadi ${ }^{1 *}$, F Apriliani ${ }^{1}$ and S Irawan ${ }^{1}$ \\ ${ }^{1}$ Department of Industrial Management, Diploma Program of Bogor Agricultural \\ University, Bogor, Indonesia \\ *s_tutur@yahoo.com
}

\begin{abstract}
Industry has to increase their competitiveness in order to make high profits and customer satisfaction. One of its efforts is the application of TPM (Total Productive Maintenance) in any machine production to maximize effectiveness of machine. The OEE (Overall Equipment Effectiveness) is used as an indicator effectiveness of the machine that important to be measured. This research aims to know to scatter value OEE in various type industries, The data in this research were obtained from collecting students' final task reports on Industrial Management Program Diploma IPB who has done internship program in the industry with the topic Total Productive Maintenance. The results indicate that average OEE value in FMCG, Textile, Chemical Industry and Manufacture Components are more than $60 \%$ but lower than $85 \%$, so that is still below the value of the world class industry. Furthermore, availability score has reached world class standard, while performance and quality is still below world class.
\end{abstract}

\section{Introduction}

To make high profit, Industry has to increase their competitiveness and achieve customer satisfaction. However national industry has lower competitiveness comparing multinational industry so that one of efforts is optimizing usage of machine as production facilities. The machine is always in good condition which is able to solve problem quickly like breakdown or repairing maintenance. Because of that, implementing TPM (Total Productive Maintenance) has to be supported which has aim to optimize availability and performance machine and also reduce defect product. The indicator of TPM system is OEE score that is used by many industries in whole world because it is easy to measure a gap between existing condition and target performance machine. A proper maintenance is shown by high OEE score which can trace an area to be improved. A maintained machine will improve quality, give maximum capability and increase worker moral so the competitiveness of company would increase. Measuring of OEE score can be in one machine or many machines in a line production. Nowadays, there are no studies in Indonesia which calculate OEE score in macro scale. This research has aim to compare OEE score in macro scales.

\section{Literature Review}

There are many researches about calculation OEE that is used as indicator to improve production efficiency in many kind of industries because there are most common and popular in the production industries. Vijayakumar and Gajendran (1) has researched that the OEE of the injection moulding 
process was increased from $61 \%$ to $81 \%$ through the implementation of availability, better utilization of resources, high quality products and also raised employee morale and confidence. In addition, Zandieh et al. (2) used OEE in continuous processes for refinery Stabilization units and had a result that although the Overall Equipment Effectiveness coefficients of the investigated process are not at the world class level, but if try to improvement continuously, their performance are acceptable. In fastmoving consumer goods (FMCG), Baluch (3) has used OEE in palm oil mills and stated that collecting the data for OEE will teach the operator about the equipment, focus the operator's attention on the losses; grow a feeling of ownership of the equipment. Similarly Vijayakumar and Gajendran (1) and Gupta and Garg (4) reported case studies on implementing TPM in an automobile manufacturing component organization and achieved a successful implementation TPM by increasing OEE score. The lack of those research is no explain in macro scale only in specific case meanwhile this research has an OEE score averagely in many industries. On the other hand, this research has a similar method with Maiden et al. (5) that has built a practical framework to implement OEE and a case study to explain in detail each steps proposed. The proposed framework is beneficial to the engineer especially the beginner to start measure their machine performance and later improve the performance of the machine.

\section{Research Method}

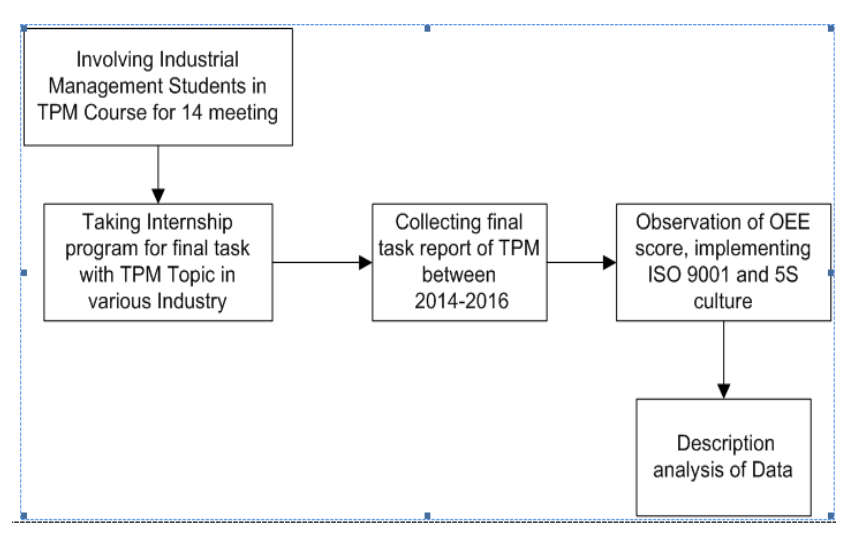

Figure 1. Research methodhology.

Figure 1 show the methodology of this research which data was collected from final task report of industrial management IPB students who took TPM course in 14 meeting in collage and internship program in many industries. As many as 85 final task reports have observed which represent various type industries in 2014 until 2016. The data is about OEE score, implementation of ISO 9001 and 5S program.

\section{Result and Discussion}

The objects of this research are manufacturing companies that has many kind type of manufacture goods like FMCG (Fast Moving Consumer Goods), Textile, Chemical Industries andManufacture Component where those are in West Java, Central Java and East Java. It almost 81,2\% of companies has achieved ISO 9001 certification meanwhile 18,8\% has not certified ISO 9001 so that almost companies have considered about the important of continuously quality management. However, to make easy in implementing Total Productive Maintenance, companies need to start with good 5S culture. Based on observation, 54,1\% of companies have good activities in implementing 5S culture, $40 \%$ is fair enough and $5.9 \%$ has not yet maximal in implementing $5 \mathrm{~S}$ culture. Because of that, to evaluate and indicate how effective the operational of manufacture, it has to be measured Overall Equipment Effective (OEE) score. The 100\% of OEE shows a perfect production activities that produce quality goods and no stop line production time. 


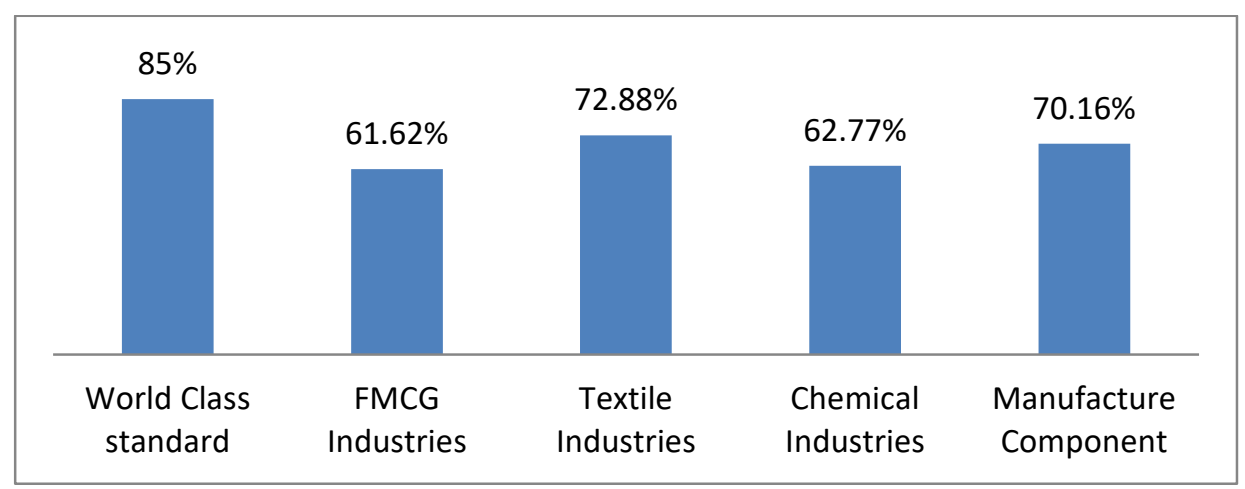

Figure 2. OEE scores in various type industry.

Based on Figure 2, there are a different score among 4 type companies and none achieving world class score of OEE with $85 \%$ score. It can be seen the highest OEE is textile companies with 72,9\% and the lowest score is FMCG companies with $61,62 \%$. All type of companies is above $60 \%$ but still below $80 \%$. The score is typical in many kinds of company that indicate many opportunities to improve and develop production TPM system. If OEE score is $40 \%$, it can be increased by simple step like tracing the reason of stop time and handling the priority of breakdown problem. The classification type of OEE world class standards is provided by Figure 3.

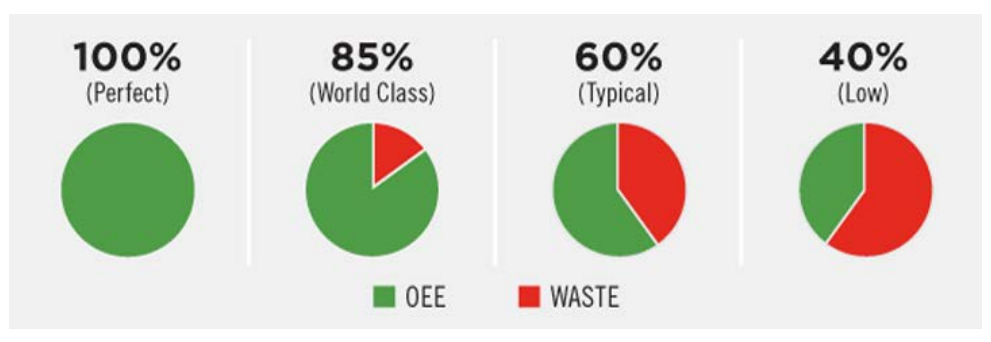

Figure 3. The classification type of OEE world class standards.

The average of OEE in manufacturing companies in the world is around $60 \%$ (6), however $85 \%$ is the type of world class manufacturing that is achieved by $90 \%$ Availability, 95\% Performance and 99\% Quality Yield. Because of that, there are many chances to improve OEE in manufacture companies. Based on observation, the average of availability score for 4 type industry is $90.53 \%$, performance score is $75.44 \%$ and Quality Yield is $98.12 \%$. Availability has achieved the world class standard but Performance and Quality yield score has not yet achieved the world class standard. For conclusion, OEE is below world class standard which score is $66 \%$ averagely. Figure 4 shows the differences of world class standard and actual observation in terms of Availability, Performance and Quality. 


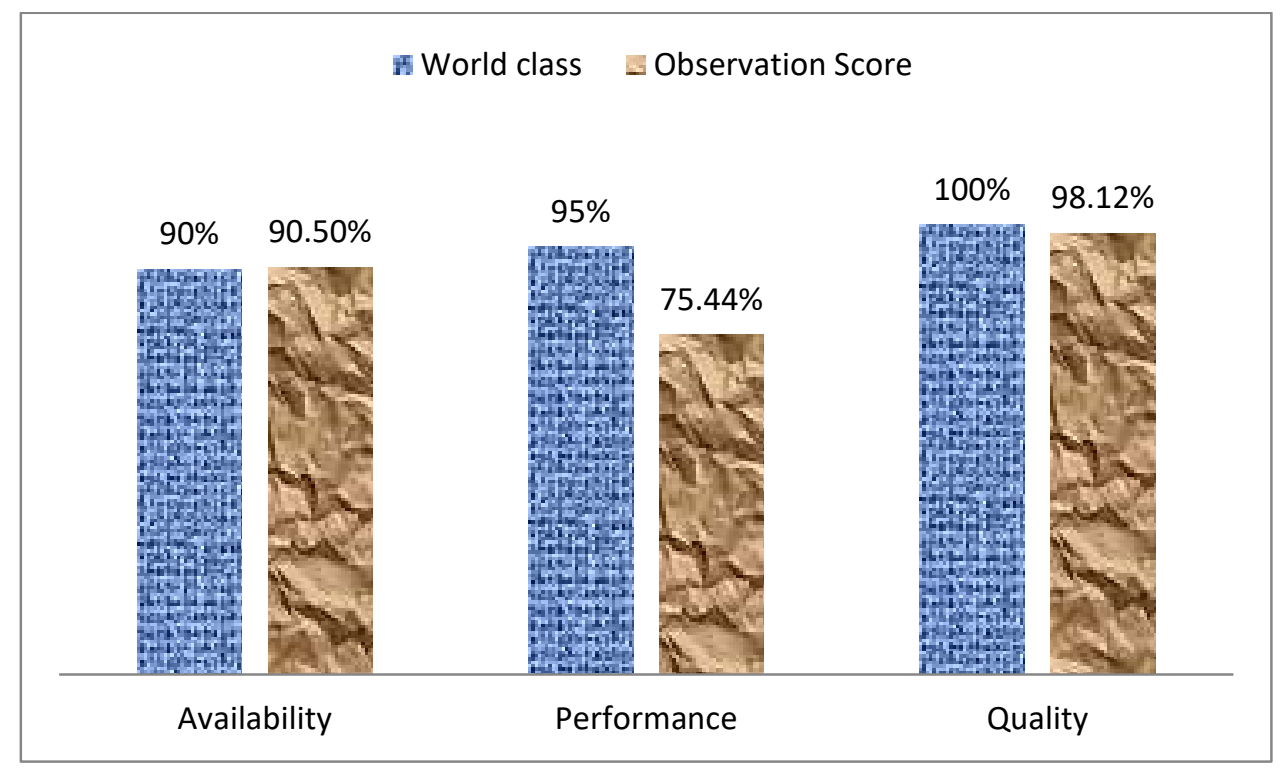

Figure 4. The differences of OEE world class standards and observation score.

This research show even though OEE is below world class standard, companies can try to improve continually because some companies has achieved ISO 9001 and implemented 5S properly. Samad et al. (7) has stated that OEE in one of ship manufacturing company has lower OEE which is $35 \%$ but it has a chance to increase OEE score. Low score of OEE is caused by reasons which are speed loss on machine, set up or adjustment time, idle time and minor stop. Speed loss means the differences between capacity design and actual capacity. The other reasons are reduced yield that occurs in beginning production caused by start stabilization phase, quality loss that indicate defect product which is caused by machine malfunction. For overall, downtime losses is connected with availability score, speed loss can change with performance and quality loss can influence quality yield score on OEE calculation. On the other hand, OEE score is not only caused by internal machine but also external factor such as skill level of operator, formulating material, facilities, availability of material, scheduling and etc. Vivekprabhu et al. (8) has found that the lagging in performance rate contributes more than availability rate and quality rate that deficiency of effectiveness in the system. It is concluded that maintaining the performance rate above $95 \%$ will result in effective utilization of the considered manufacturing system.

OEE implementation generally is based on motivation of company management to be an indicator how to analyze resources that use on shop floor manufacture. If a company has many production facilities it would be useful to implement OEE so that the top management can compare one facilities to other facilities. Meanwhile, Implementing OEE can identify potencies which can be used and support lean manufacturing as a tools to improve process and eliminate waste. Company who develop hidden capacity by tool management is cheaper ten times than company who develop new capacity or new facilities.

\section{Conclusion}

It is essential for a company to improve the production rate and quality of the products by implementing OEE calculation. The lack of research today is no explain in macro scale only in specific case meanwhile this research has an OEE score averagely in many industries with the same calculation procedures. This research has studied an OEE score in FMCG, textile, chemical and component manufacture based on final task reports of industrial management IPB student. The results indicate that average OEE value in FMCG, Textile, Chemical Industry and Manufacture Components are more than $60 \%$ but lower than $85 \%$, so that is still below the value of the world class industry. 
However there are chances to increase OEE score by continues improvement and commitment of top management. Furthermore, availability score has reached world class standard, while performance and quality is still below world class.

\section{References}

1. Vijayakumar SR, Gajendran S. Improvement of Overall Equipment Effectiveness (OEE) in injection moulding process industry. IOSR J Mech Civ Eng Spes Issue. 2014;2:2278-1684.

2. Zandieh S, Tabatabaei SAN, Ghandehary M. Evaluation of Overall Equipment Effectiveness in a Continuous Process Production System of Condensate Stabilization Plant in Assalooyeh. Interdiscip J Contemp Res Bus. 2012;3(10):590-8.

3. Baluch N, Sobry Abdullah C, Mohtar S. Measuring OEE in Malaysian Palm Oil Mills. Interdiscip J Contemp Res Bus. 2012;4(2):733-43.

4. Kumar Gupta A, Garg RK. OEE Improvement by TPM Implementation: A Case Study. Int J IT, Eng Appl Sci Res Int Res J Consort. 2012;1(1):2319-4413.

5. Maideen NC, Sahudin S, Yahya NHM, Norliawati AO. Practical Framework: Implementing OEE Method in Manufacturing Process Environment. IOP Conf Ser Mater Sci Eng. 2016 Feb;114(1):12093.

6. $\quad$ Leflar J. TPM at Hewlett-Packard. Las Vegas, Nevada; 1999.

7. Samad MA, Hossain MR, Asrafuzzaman M. Analysis of Performance by Overall Equipment Effectiveness of the CNC Cutting Section of a Shipyard. ARPN J Sci Technol. 2012;2(11):1091-6.

8. Vivekprabhu M, Karthick R, Senthil Kumar G. Optimization of Overall Equipment Effectiveness in A Manufacturing System. Int J Innov Res Sci Eng Technol. 2014;3(3):1192-6. 